\title{
A Study on Urban Growth Boundary Delimitation: The Case of Baoji, Weinan and Ankang Urban Master Plan
}

\author{
Guo Qiwei ${ }^{1,2, *}$ Chen Xiaojian $^{2}$ and Zhu Yucong ${ }^{1,2}$ \\ ${ }^{I} X i$ 'an University Architecture \& Technology, NO.13, Yanta Lu, Xi'an, Shaanxi, China; ${ }^{2}$ Chang'an University, Middle \\ Section of Nan Erhuan Road, Xi'an, Shaanxi, China
}

\begin{abstract}
This paper analyzes urban growth boundary delimitation in the urban master plan in Shaanxi Province and chooses Baoji, Weinan and Ankang as the research object. The three cities have delimited urban growth boundaries. This paper compares interrelationships between urban spatial structure, urban size, delimitation of the four areas, boundaries of planning area, natural boundaries, artificial boundaries and central urban area urban growth boundary delimitation. Based on the analysis of influence factors of urban growth boundary delimitation in central urban areas the three cities, this paper puts forward suggestions on detailing regulations, perfecting contents, highlighting timeliness and emphasizing on coordination.
\end{abstract}

Keywords: Delimitation, urban growth boundary, urban master plan.

\section{INTRODUCTION}

In its The Measures for Formulating Urban Planning adopted in 2006, China put forward the concept of "urban growth boundary" for the first time. Some Chinese cities then begun to delimit urban growth boundaries in formulating their master planning. The state-level meeting on pushing urbanization held in December 2013 required that in formulating urban planning, the planners should gradually transform from the expansionary planning to the one that features with delaminated urban boundary and optimized spatial structure. Delimitating urban boundary, as put forward in the meeting, refers to the fact that we should define a reasonable growth boundary for urban expansion. The meeting set out the direction for formulating urban master plans.

Chinese scholars have conducted researches on delimitating and applying urban growth boundary (UGB) from various perspectives. From the perspective of legislation, Huang Minghua et al. (2008) conducted in-depth research [1] on the adaptability of UGB in accordance with Chinese urban characteristics. Feng Ke et al. (2008) analyzed the connotation and efficacy of UGB theoretically, highlighting the necessity of delimiting UGB [2]. Duan Degang et al. (2009), started from probing the reasons of delimiting UGB, compared the differences between China and the US, concluding that cultivated land protection served as a major cause for China to delimit UGB [3]. Zhang Xueyong et al. (2012) explored the driving as well as constrain mechanisms of UGB [4]. Wang Guo'en et al. (2012) studied the relevance between administrative district division adjustment and UGB [5]. Zhang Guoqiang (2011) probed the delimitation methods for urban growth boundary from land suitability evaluation [6]. Based on the analysis to the orientation of spatial structure, Zhang
Zhenguang et al. (2013) put forward the methods to delimit the rigid and flexible UGBs [7]. The current researches on UGB mainly focus on theoretical construction and delimitation methods. This paper, by analyzing UGB delimitation in formulated master plans, explores the problems in current UGB delimitations and proposes advices for further UGB delimitations.

\section{PROSPECTUS OF THE CASES}

Shaanxi Province governs ten cities, in which the master plans of seven cities were formulated after the adoption of Measures for Formulating Urban Planning in 2006 (Table 1). Among those seven cities, the master plans of Baoji, Weinan and Ankang have clear UGB delimitations in their central urban areas. This paper takes Baoji, Weinan and Ankang as the research subject.

UGB is used for control urban development scale and delimitating urban construction scope [1]. The excessive expansion of urban space will result in massive idle lands and infrastructures [8], thus UGB serves as an effective tool to control the urban sprawling and gives prominence to the guiding role of master plans. According to The Measures for Formulating Urban Planning (2006), we need to consider UGB for central urban areas while formulating master plans so as to provide basis for deciding construction land scales. As The Measures has no clear specification for the form and result representation of UGB research, this paper adopts different methods and representation forms in delimiting and research UGB of central urban areas.

\section{INFLUENCING FACTORS IN DELIMITING UGB}

\subsection{The Relationships Between Urban Spatial Structure} and UGB Delimitation

UGB plays a directive role in shaping the features of urban spatial structure, and different urban spatial structures, in 
Table 1. Master planning of cities in case study.

\begin{tabular}{|c|c|c|c|c|c|c|c|c|}
\hline \multirow[b]{2}{*}{ No. } & \multirow[b]{2}{*}{ City } & \multicolumn{3}{|c|}{ Planning Term } & \multicolumn{4}{|c|}{ UGB Delimitation of Central Urban Areas } \\
\hline & & Base & Short & Long & $\begin{array}{c}\text { Drawing } \\
\text { Delimitation }\end{array}$ & $\begin{array}{c}\text { Text } \\
\text { Description }\end{array}$ & Specific Scope & Planned Area \\
\hline 01 & Baoji & 2010 & 2015 & 2020 & Yes & Yes & Yes & Yes \\
\hline 02 & Weinan & 2009 & 2015 & 2020 & Yes & Yes & Yes & No \\
\hline 03 & Ankang & 2010 & 2015 & 2020 & Yes & Yes & Yes & No \\
\hline 04 & Yulin & 2007 & 2010 & 2020 & \multicolumn{4}{|c|}{ No } \\
\hline 05 & Yan'an & 2012 & 2015 & 2030 & \multicolumn{4}{|c|}{ No } \\
\hline 06 & Hanzhong & 2011 & 2015 & 2020 & \multicolumn{4}{|c|}{ No } \\
\hline 07 & Shangluo & 2009 & 2015 & 2020 & \multicolumn{4}{|c|}{ No } \\
\hline
\end{tabular}

Table 2. The characteristics of urban spatial structure and urban growth boundary delimitation.

\begin{tabular}{|c|c|c|c|c|c|}
\hline No. & Name & Spatial Structure Features & $\begin{array}{c}\text { Construction Land } \\
\text { Scale (KM } \mathbf{K}^{\mathbf{2}}\end{array}$ & $\begin{array}{c}\text { UGB Area } \\
\left(\mathbf{K M}^{\mathbf{2}}\right)\end{array}$ & $\begin{array}{c}\text { Urban Planning Zone } \\
\text { Area (KM }\end{array}$ \\
\hline \hline 01 & Baoji & Belt clusters (1 city 5clusters) & 143 & 355 & 3574 \\
\hline 02 & Weinan & Clusters (1 city 3clusters) & 75 & 690 & 7376 \\
\hline 03 & Ankang & Clusters (1 city 6 clusters) & 57 & 450 \\
\hline
\end{tabular}

turn, influence the delimitations of UGB [7]. Different urban spatial structures also generate various land demands, affecting the scales of UGB delimitations. The three cities enjoy similar urban spatial structure features: they all have rivers run across their middle areas and their master plans adopt the cluster development pattern. The central urban spatial structure of Weinan is a classic cluster pattern. Its main city zone cluster is some $10 \mathrm{~km}$ away from Huazhou cluster. When delimiting UGB for the central urban area of Weinan, the green lands between Weihe River and clusters, and many city periphery ecological green belts were comprised into UGB, making the land area within UGB is nine times larger than the long-term urban construction land area. Baoji also adopts a cluster pattern for its urban spatial structure and Weihe River runs across its middle area. Its five planned clusters, however, are comparatively more compact and its UGB comprises the waters between clusters and some mountains in cluster outskirts. The land area within its UGB is 2.48 times larger than its long-term urban construction land area. The master planning of Ankang was made out when delimiting UGB of its center urban area as per the features of urban spatial structures. The UGB includes ecological green belts between clusters and some water areas. The land area within UGB is 1.28 times larger than its long-term urban construction land area (Table 2). We can see that, by comparing the areas of UGBs, even though the three cities enjoy same spatial structures, their UGBs vary greatly. The major reason for causing the difference lies in that the identifications to their water areas and ecological green belts were different when delimiting UGBs for the central urban areas of the three cities.

\subsection{The Relationships Between Urban Scale and UGB}

From 2000 to 2009, the period before formulating master planning, the annual average growth rate (AAGR) of urban construction lands was faster than AAGR of population in Baoji, Weinan and Ankang (Table 3). From 2008 to 2012, the growth speeds of built-up areas in Baoji and Ankang were far faster than their growth speeds of urban population (Table 4). According to the actual growth speed in recent years, the urban land use scales in those two cities will drastically exceed the planned land use scales in those two cities. Their predicted population and land use growth in master planning have difference with the actual urban development. Comparing the predictions in three cities, we can see that Weinan took the fastest speed in population and land use growth speed (Table 5). Seeing the statistics from 2008 to 2012, however, Weinan took the slowest speed in built-up area and urban population growth, accounting for less than half of the predicted growth speed in master planning. The actual annual population growth rate in Weinan City has not reached half of the predicted growth rate in master planning.

By comparing population and land scale changes before and after the formulations of master plans, and after the affirmation of master plans of the three cities, we can see that:

Firstly, the growth speed of population is inconsistent with the growth speed of land scales;

Secondly, the predicted values in mater plans have huge differences with the actual growth values.

We can see, by comparing the growths of land scales and population sizes, that the expansion speed of urban construc- 
Table 3. Change of the scale of current urban construction land and population.

\begin{tabular}{|c|c|c|c|c|}
\hline No. & Name & Time & Construction Land AAGR & Population AAGR \\
\hline \hline 01 & Baoji & $2000-2007$ & $7.5 \%$ & $4.6 \%$ \\
\hline 02 & Weinan & $2001-2009$ & $3.83 \%$ & $3.31 \%$ \\
\hline 03 & Ankang & $2000-2008$ & $5.11 \%$ & $5.00 \%$ \\
\hline
\end{tabular}

Table 4. Data of urban built-up areas in the research during 2008-2012.

\begin{tabular}{|c|c|c|c|c|c|c|c|c|c|}
\hline \multirow{2}{*}{ No. } & \multirow{2}{*}{ Name } & \multicolumn{4}{|c|}{ Built-up Urban Area } & \multicolumn{4}{c|}{ Urban Population } \\
\cline { 3 - 11 } & & $\begin{array}{c}\mathbf{2 0 0 8} \\
\left(\mathbf{K M}^{\mathbf{2}}\right)\end{array}$ & $\begin{array}{c}\mathbf{2 0 1 2} \\
\left.\mathbf{( K M}^{\mathbf{2}}\right)\end{array}$ & AAGR & $\begin{array}{c}\text { Increase } \\
\left(\mathbf{K M}^{2}\right)\end{array}$ & $\begin{array}{c}\mathbf{2 0 0 8} \\
\mathbf{( 1 0 , 0 0 0 )}\end{array}$ & $\begin{array}{c}\mathbf{2 0 1 2} \\
\mathbf{( 1 0 , 0 0 0 )}\end{array}$ & $\begin{array}{c}\text { AAGR } \\
\text { Increase } \\
(\mathbf{1 0 , 0 0 0 )}\end{array}$ \\
\hline \hline 01 & Baoji & 71.37 & 97.78 & $8.2 \%$ & 28.41 & 72.71 & 88.25 & $4.96 \%$ & 15.54 \\
\hline 02 & Weinan & 38.20 & 42.50 & $2.7 \%$ & 4.3 & 37.21 & 42 & $3.07 \%$ & 4.79 \\
\hline 03 & Ankang & 29.00 & 37.50 & $6.64 \%$ & 8.5 & 30.10 & 32.04 & $1.57 \%$ & 1.94 \\
\hline
\end{tabular}

Note: Urban population includes temporary residents in cities concerned. Data from: China Urban Construction Statistical Yearbook, complied by the Ministry of Housing and Urban-Rural Development

Table 5. Change of urban construction land scale and population during planning period.

\begin{tabular}{|c|c|c|c|c|c|c|c|}
\hline \multirow{2}{*}{ No. } & Name & $\begin{array}{c}\text { Construction } \\
\text { Land AAGR }\end{array}$ & $\begin{array}{c}\text { Central Urban Land Area by } \\
\text { the End of Planning (KM } \mathbf{K M}^{2}\end{array}$ & $\begin{array}{c}\text { Population } \\
\text { AAGR }\end{array}$ & $\begin{array}{c}\text { Population by the } \\
\text { End of Planning }\end{array}$ & \multicolumn{2}{|c|}{$\begin{array}{c}\text { Prban Development Land } \\
\text { Papita (M⿻丷木 }\end{array}$} \\
\hline \hline 01 & Baoji & $4.28 \%$ & 143 & $3.24 \%$ & 130 & 96.6 & 110 \\
\hline 02 & Weinan & $6.07 \%$ & 114 & $6.29 \%$ & 102 & 101.24 & 96.91 \\
\hline 03 & Ankang & $5.74 \%$ & 57.46 & $4.32 \%$ & 60 & 81.7 \\
\hline
\end{tabular}

tion lands has exceeded the reasonable scope. UGB is delimited as per factors including the demand of urban population growth [2]. As population and land scales are importance basis for delimitating UGB, the inaccurate predictive values will result in unreasonable UGB delimitation in the master plan, incurring UGB fail to play its role as a controller in planning.

\subsection{The Relationships Between Urban Planning Area Boundary and UGB}

Planning area refers to the zone that must be controlled so as to meet the demands of rural and urban development demands. In formulating a master plan, we must identify the boundary of the urban planning area. The relationships between urban planning area boundary and UGB in the master plans of three cities fall into two categories:

\subsubsection{The Planning Area Scope is Larger than the Control Scope of UGB for Central Urban Area}

In its master plan, Ankang listed these famous places of interest which keep a close relation with it to planning area scope (Fig. 1). In delimiting its UGB for central urban area, however, Ankang included some water areas and farm lands but excluded the places of interest.

\subsubsection{The Planning Area Scope Overlaps with UGB of Central Urban Area}

The UGB of Luyang Lake cluster in the master plan of Weinan overlaps with the planning area scope of Luyang Lake Modern Comprehensive Industrial Development Zone (Fig. 2). The unified delimitation of planning area and

UGBs facilitates the integrated control and management to lands in the development zone.

\subsection{The Relationships Between UGB and "Four Areas"}

From the time order of formulating a master plan, the "four areas" (non-construction area, construction limited area, construction suitable area and built-up area) are set out earlier than the delimitation of the spatial growth boundary. The delimitations for the boundaries of "four areas" provide reasonable basis for studying the spatial growth boundary of central urban area, deciding the construction land scale and identifying the scope of construction lands. The delimitations of "four areas" and the spatial growth boundary of central urban area both mean to categorize the lands in the planning area. The delimitation of "four areas" is based on land evaluation, thus it is the evaluation to the present state of land use, while UGB is based on the future sustainable de- 


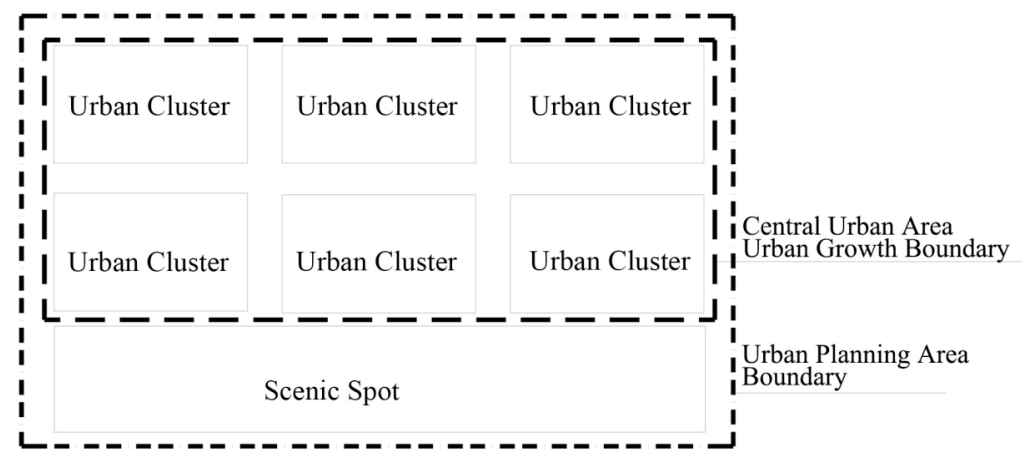

Fig. (1). The planning area boundary and central urban area urban growth boundary of Ankang.

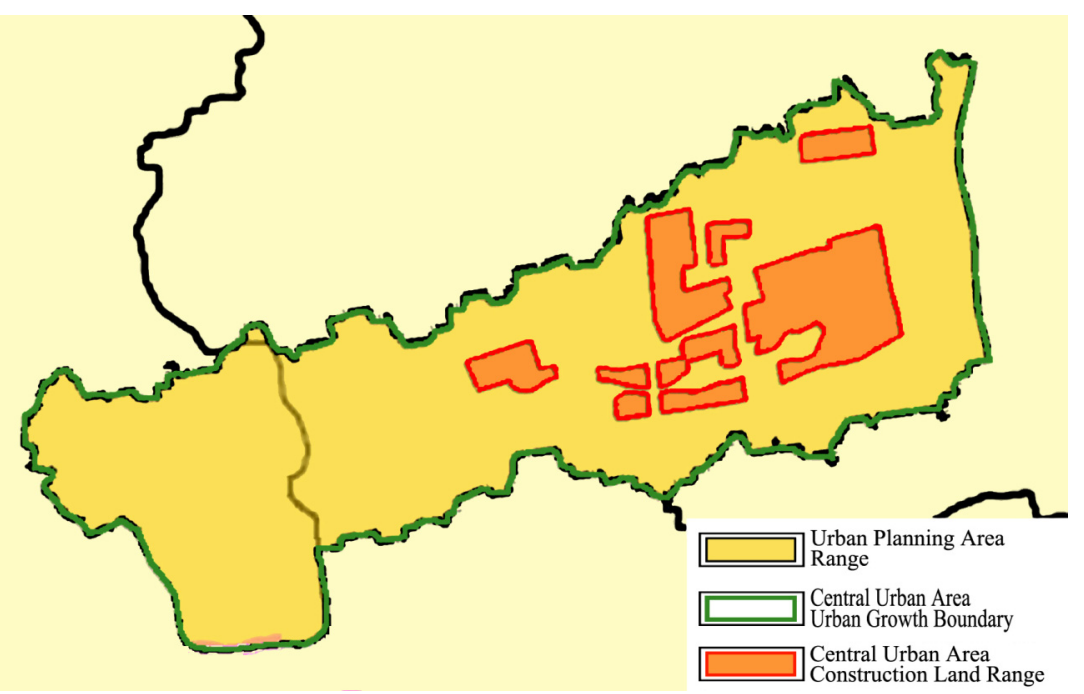

Fig. (2). The scope of planning area and central urban area urban growth boundary in Weinan Luyang Lake cluster.

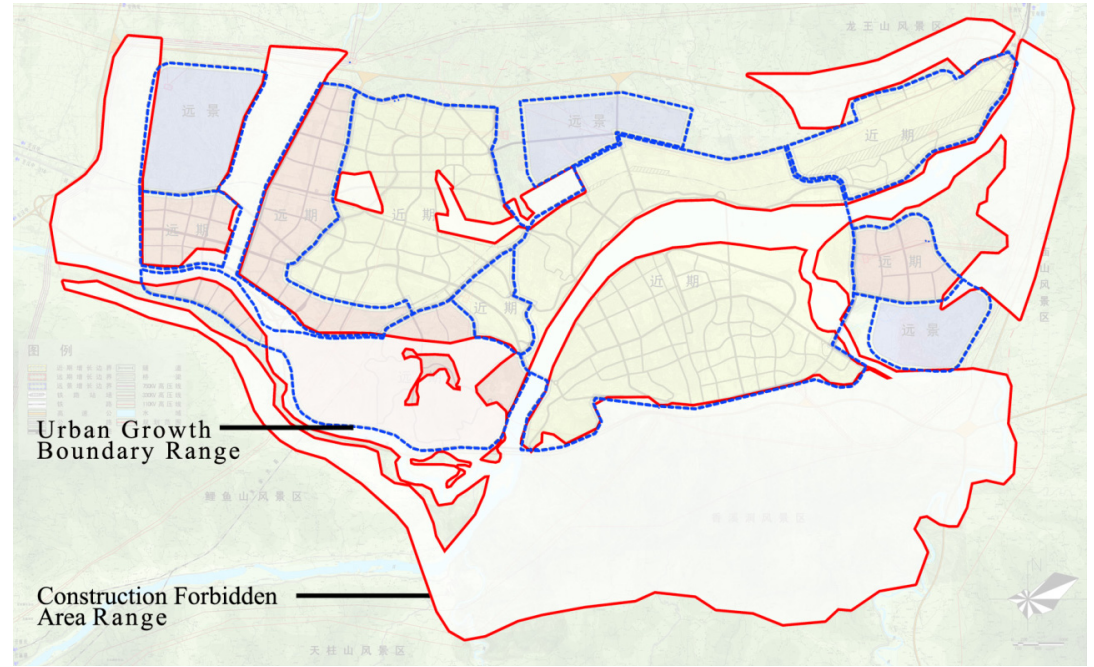

Fig. (3). Non-construction area and central urban area urban growth boundary in Ankang master plan.

velopment of a city, so it is the prediction to future. We may encounter the overlapping of "four areas" boundaries and growth boundaries (Fig. 3). The master plans of three cities in this paper all have the so-called "four areas". The overall urban master plans list a number of non-construction areas into UGBs, which goes against the original intention of delimiting UGB.

\section{REFLECTIONS ON DELIMITING UGB}

\subsection{Detailing the Management Rules on UGB Delimitation}

\subsubsection{Setting Out Rules and Standards}

Economically backward cities in west and middle China compete with other cities mainly by large scale land devel- 
opment and transferring urban land at low prices [9]. The competition will finally result in uncontrolled urban scales and the waste of urban lands. From the experiences that the US gained in managing urban land, UGB serves as an effective tool to check urban expansion and develop infrastructure in an ordered way [10]. We thus can see that UGB has great significance to urban planning, the current rules and standards, however, fail to make related interpretations on how to delimit UGB, and how to control and implement post management after delimitation, incurring different planning units have their respective understandings and methods in delimitating UGBs. To effectively guide the formulation of urban master plans, related articles, rules and standards concerning UGB delimitation should be unified.

\subsubsection{Adjusting the Mandatory Content of Urban Master Plans}

In current measures to formulate urban planning, the delimitation of UGB does not belong to the mandatory content, thus UGB has very little effect in controlling urban expansion. The formulating measures should make clear the principles and methods to delimit UGB in urban master plans to strengthen the role of UGB in urban plan. To give prominence to the control and management functions of UGB to urban expansion, we should adjust the mandatory content of the overall master plan, adding UGB into the mandatory content.

\subsection{Specifying the Content of UGB Delimitation}

\subsubsection{The Spatial Attributes of UGB Delimitation}

The spatial attributes of UGB should be reflected on the two-dimensional lands. The very first intention of delimitating UGB is to set a boundary to divide city and countryside, so we have to make clearer specifications for the attributes of UGB in the master plan. The attributes of UGB are reflected in spatial scope and area. In reviewing related cities, I found that most cities only delimited the spatial scope of UGB without giving the specific control area, meaning that many cities hold different understandings towards the delimitation content of UGB in their urban master plans. Therefore, the technical guidance for delimitating UGB can be set to specify the scope, technical process, operation principle and requirements for presenting achievements, providing technical support for delimitating UGB.

\subsubsection{UGB Delimitation Levels}

The Urban and Rural Planning Law stipulates that the municipal governments are responsible for formulating urban master plans. Due to the limitation of research scope and the complexity of interest demands, however, deviations from budgeting urban scales in formulating master plans may occur, causing the delimitation of UGB unreasonable. Responding to various uncertainties in urban development, we may delimit the rigid UGB to make clear the eternal controlled scope, and considering urban development is a gradual process, we may also delimit flexible UGB with specific term to gradually direct the future urban development. For the current planning formulation system, we may to analyse the UGB pattern of a governed city under the provincial urban planning system formulated by the provincial or autonomous region government, and we can also, according to the urban development strategy, set out the specific basis for delimitating UGB and identify the rigid UGB for a governed city. According to different developments of cities, we can, in formulating the urban master plan, take the rigid UGB delimited in the provincial planning as basis to set out the flexible UGB with different phases.

\subsection{Emphasizing on the Timeliness of UGB Delimitation}

Portland delimited its UGB in 1980, stipulating that "the lands within IGB can be developed immediately, the lands outside IGB but within UGB are not allowed to develop in ten years and the lands outside UGB can not be developed before 2000 (in 20 years)." [11] The formulation of urban master plans takes specific timelines. Generally, an urban master plan has short-term and long-term timelines, namely, 5 years and 20 years, respectively. Some urban master plans also have far-seeing planning. In delimitating UGB for an urban master plan, we may make delimitations by phases. The urban development scope at each phase is just the UGB at that time, reflecting the timeliness of UGB. This method provides a scientific basis for managing urban spatial development at various phases. According to the time phase system in Chinese urban planning formulation system, the author suggests to set out short-term UGB (5 years), longterm UGB (20 years) and far-seeing UGB (50 years).

\subsection{Pushing the Coordination for UGB Delimitation}

\subsubsection{Coordination with Related Planning}

In its Advices of Formulating the Overall Planning of Municipal, County and Town Land Use (No. 2009-51), the Ministry of Land Resources stipulates that the areas for rural and urban construction lands should be see out, and the city, town, village industrial and mining boundaries should be delaminated as per the overall land use planning.

The state-level meeting on pushing urbanization held in December 2013 required that we should enhance the urban construction land utilization efficiency, protect agricultural spaces including arable, garden and vegetable fields, and define ecological lines. The meeting also claimed that urban planning should gradually change from expansive planning to the planning that delimits urban boundary and optimizes spatial structure. We can see that even top Chinese authority has attached strategic significance to protect agricultural lands and reasonably control urban scale. The delimitation of UGB, in formulating master plans, should take the boundaries of ecological lines and construction lands as basis, and coordinate with land use planning and environmental protection planning.

\subsubsection{The Coordination of Various Boundaries in Master Plan}

UGB, urban planning area boundary and the boundaries of "four areas" jointly serve as a scale-plate to control urban expansion in a reasonable way. Only by making clear the roles and interrelationships of various boundaries in master plans can we ensure them to guide and control urban development. In formulating a master plan, UGB delimitation for central urban area should be closely related with the boundary delimitations of "four areas" (Fig. 4). 


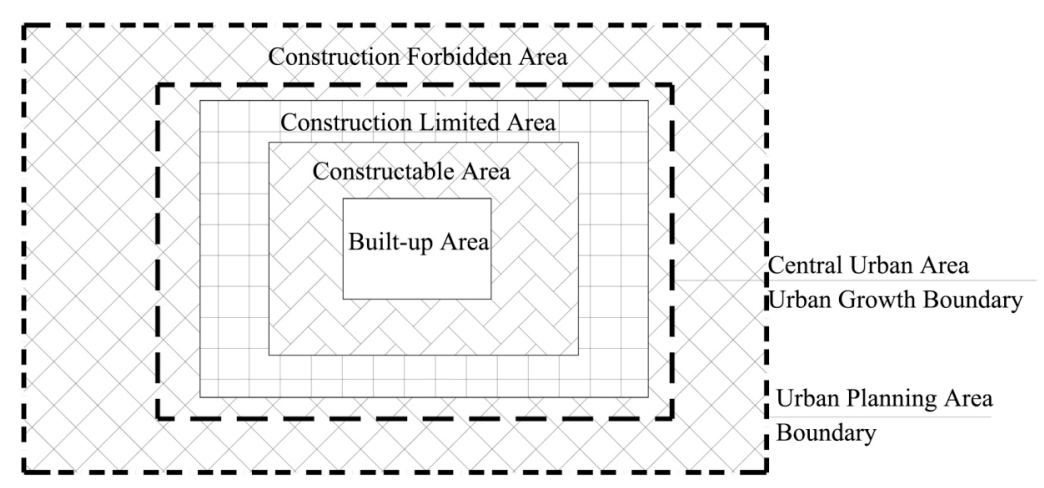

Fig. (4). Relations of various boundaries and UGBs of central urban areas in urban master plans.

The lands used in boundaries may be composed by builtup areas, construction suitable areas, construction limited areas and some non-construction areas. The first three areas fall into the entity construction scope controlled by UGB. The fact that comprises some non-construction areas into UGB aims at better pushing ecologically safe urban development. Those non-construction areas may include parks, forestry lands, lakes, rivers and wetlands in suburb, providing various ecological protection barriers for a city.

\section{CONCLUSION}

This paper analyses UGB delimitation in formulating the master plans of cities governed by Shaanxi Province, discusses the issues concerning the seriousness, standard and rationality of the delimitation, and puts forward suggestions for improvement from technical and implementation perspectives, providing certain references for the following planners to take for. It should be noted that the UGB delimitation, from the adoption of The Measures for Formulating Urban Planning in 2006, has been carried out for only seven years. As the formulations of urban master plans take a long time, some of the master plans analysed in this paper got approvals from the governing authorities only 2 or 3 years ago, thus the relationships between urban spatial expansion and UGB have not been fully demonstrated. The verification to the effect of UGB delimitation by consistency analysis to the actual UGB and planned UGB, therefore, needs to be further studied.

\section{CONFLICT OF INTEREST}

The authors confirm that this article content has no conflict of interest.

\section{ACKNOWLEDGEMENTS}

This work is supported by the National Natural Science Foundation, China (No. 51378420), Social Development
And Scientific Research Projects of Shaanxi, China (No. 2015SF294), Social Science Funds Projects Of Shaanxi, China (No.2014D39), Fundamental Research Funds for the Central Universities (Humanities And Social Sciences) Projects (No.310841155032) and also by 2014 Subsidy Programs Of Science And Technology Funds Of Housing And Urban-Rural Development in Shaanxi Province Soft Science (No. 2014-R80).

\section{REFERENCES}

[1] M. Huang, and X. Tian, "Reflection on urban growth boundary in the new urban planning formulation means", Planner, vol. 6, pp. $13-15,2008$.

[2] K. Feng, C. Wu, S. Wei, and Y. Liu, "Research on urban growth boundary: theoretical analysis and its application in China", Economic Geography, vol. 3, pp. 425-429, 2008.

[3] D. Duan, and F. Wang, "Analysis on urban growth boundary under the background of urban development in China" City, vol. 2, pp. 42-45, 2009.

[4] X. Zhang, T. Shen, and X. Zhou, "Urban growth boundary formation mechanism" Planner, vol. 3, pp. 28-34, 2012.

[5] G. Wang, and Y. Zhang, "Urban growth boundary efficacy and its influence on administration boundary adjustment", Planner, vol. 5, pp. 21-27, 2012.

[6] G. Zhang, "Research on Urban Growth Boundary in Central Urban Areas of Yan'an", Xi'an University of Architecture and Technology, China, 2011, pp. 25-30.

[7] Z. Zhang, and S. Zhang, "The ideas and methods of spatial structure-oriented urban growth boundary delimitation", City Planning Forum, vol. 4, pp. 33-41, 2013.

[8] C. Zhou, and C. YE, "Features and causes of urban spatial growth in Chinese metropolises", Journal of Geographical Sciences, vol. 6, pp. 728-738, 2013.

[9] P. Wang, "Research on Institutional Constraints and City Size in China", Zhejiang University, Hangzhou, 2012, vol. 19.

[10] X. Wang, S. Luo, Local Governments and Regional Governing in the Metropolitan America, Xiamen University Press, China, 2010, p. 187.

[11] Written by lincoln institute of land policy, translated by the information center of the ministry of land and resources of people's republic of China. land planning management- experiences and lesions of land use and utilization in oregon. China Dadi Press, China, 2003, vol. 33. 